Esta revista forma parte del acervo de la Biblioteca Jurídica Virtual del Instituto de Investigaciones Jurídicas de la UNAM

\title{
El acceso a la educación desde una mirada igualitaria: la influencia del derecho internacional de los derechos humanos
}

Access to Education from an Equality Perspective:
The Influence of the International Human Rights

\author{
L'accès à l'éducation d'après un regard \\ égalitaire: l'influence du droit international \\ des droits de l'homme
}

\section{Liliana Ronconi*}

\begin{abstract}
SUMARIO: I. Introducción. II. Obligación de no discriminación: eliminación de todo tipo de discriminación normativa. III. Accesibilidad material: eliminación de todo tipo de barreras que de hecho impiden u obstaculizan el acceso a la educación. IV. Accesibilidad económica: garantizar la gratuidad en el acceso a la educación (alcance). V. Accesibilidad simbólica: adecuación para personas con discapacidad. VI. Conclusión. VII. Bibliografía.
\end{abstract}

* Doctora en derecho (UBA); especialista en Currículum y Prácticas Escolares (FLACSO Argentina). Abogada y profesora de Ciencias jurídicas (Facultad de Derecho, UBA), y profesora adjunta regular de Derechos humanos (UNPAZ). Becaria de posdoctorado Conicet. Investigadora adscripta en el Instituto de Investigaciones Jurídicas y Sociales “Ambrosio L. Gioja” (Facultad de Derecho, UBA).

Artículo recibido el 7 de marzo de 2017 Aprobado para publicación el 25 de septiembre de 2017 
RESUMEN: Hablar de derecho a la educación implica necesariamente hablar de inclusión. Todos y todas deben recibir educación (estar dentro del sistema), pero bajo ciertas condiciones. En este trabajo, me propongo analizar, conforme al derecho internacional de los derechos humanos, los distintos alcances que tiene tan sólo uno de los componentes del derecho a la educación: la accesibilidad. Esto me permitirá identificar el alcance de las obligaciones concretas que asumen los Estados en lo que respecta al acceso a la educación, a fin de conocer desde dónde deben mirarse, y resolverse, las frecuentes situaciones de desigualdad que se dan en materia de educación.

Palabras clave: derechos humanos, derecho a la educación, igualdad, accesibilidad, contenido.

ABSTRACT: The right of education implies inclusion. Everyone (boys and girls) must receive education (be in the system). In this paper, I propose to analyze, following the human right law, the different scopes of ones of the components of the right to education: the accessibility. This will allow me to identify the scope of the specific obligations that States assume with regard to access to education, in order to know where to look, and to solve, the frequent situations of inequality that occur in the field of education.

Key words: human rights, right to education, equality, accessibility, scope.

RÉSUMÉ: Lorsqu'on parle du droit à l'éducation il nous faut nécessairement parler de l'inclusion. L'éducation doit être reçue par tous et par toutes (être inclus dans le système). Dans cet article, je me propose d'analyser, conformément au droit international sur les droits de l'homme, les différentes portées de seulement l'une des composantes du droit à l'éducation: l'accessibilité. Celui-ci me permettra d'identifier les obligations concrètes assumées par les États concernant l'accès à l'éducation, afin de connaître depuis où les fréquentes situations d'inégalité présentes en ce qui concerne l'éducation doivent être observées et résolues.

Mots-clés: droits de l'homme, droit à l'éducation, égalité, accessibilité, contenu. 
Esta revista forma parte del acervo de la Biblioteca Jurídica Virtual del Instituto de Investigaciones Jurídicas de la UNAM

\section{INTRODUCCIÓN}

El derecho a la educación se encuentra ampliamente reconocido en diferentes instrumentos de derechos humanos ${ }^{1} \mathrm{e}$, incluso, en diversas Constituciones de los países de la región. ${ }^{2}$ Este derecho ha sido caracterizado como un derecho "llave", ${ }^{3}$ ya que se reconoce que su ejercicio es una práctica que permite el desarrollo y disfrute de otros derechos individuales y colectivos, no sólo referidos al campo económico o de capacitación para la vida profesional, sino también, y principalmente, la educación contribuye al pleno desarrollo de la personalidad y a la formación de la ciudadanía, así como al fortalecimiento del respeto a los derechos humanos.

El derecho a la educación está compuesto por las conocidas cuatro "A": asequibilidad, accesibilidad, aceptabilidad y adaptabilidad, ${ }^{4}$ asumiendo los Estados la obligación principal de garantía de ese derecho. Sin embargo, existen

1 Dentro de los instrumentos que reconocen a este derecho tenemos al Pacto Internacional de Derechos Económicos, Sociales y Culturales (artículo 13), al Protocolo Adicional a la Convención Americana sobre Derechos Humanos en materia de Derechos Económicos, Sociales y Culturales (artículo 13, inciso 2), al Pacto Internacional de Derechos Civiles y Políticos (artículo 18, inciso 4), a la Convención de los Derechos del Niño (artículo 28), a la Convención sobre la Eliminación de Todas las Formas de Discriminación contra la Mujer (artículo 10), entre otros.

2 Artículos 5o. y 75, inciso 19, de la Constitución Argentina; artículo 64 de la Constitución Colombiana; artículo 3o. de la Constitución de los Estados Unidos Mexicanos, entre otras.

3 Tomasevski, Katarina, El asalto a la educación, Barcelona, Itermon Oxfam, 2004.

4 Comité de Derechos Económicos, Sociales y Culturales, Observación General núm. 13: "El derecho a la educación (artículo 13)" (1999, en adelante OG-13), cuyo planteamiento analítico corresponde a la relatora especial de las Naciones Unidas sobre el derecho a la educación, Katarina Tomasevski. La asequibilidad implica que la enseñanza sea gratuita y financiada por el Estado, y que exista una infraestructura adecuada y docentes formados y capaces de sostener la prestación de educación. La accesibilidad consiste en que el sistema no sea discriminatorio y que se prevean medidas positivas para incluir a los más vulnerables. Por su parte, la aceptabilidad significa que el contenido de la enseñanza sea relevante, no discriminatorio y culturalmente apropiado, y de calidad. Por último, la adaptabilidad implica que la educación se modifique a medida que cambien las necesidades de la población, y que pueda adaptarse a los contextos específicos. 
Esta revista forma parte del acervo de la Biblioteca Jurídica Virtual del Instituto de Investigaciones Jurídicas de la UNAM http://www.juridicas.unam.mx/ https://biblio.juridicas.unam.mx/bjv

https://revistas.juridicas.unam.mx/

DOI: http://dx.doi.org/10.22201/iij.24487872e.2018.18.12100

diversos informes que demuestran que la desigualdad ${ }^{5}$ es un tema recurrente en la materia educativa dentro de la región. ${ }^{6}$

En este sentido, considero que, a fin de erradicar esas situaciones de desigualdad, es necesario precisar las obligaciones que tienen los Estados a la hora de hacer efectivo este derecho desde una mirada igualitaria robusta ("igualdad real de oportunidades"). ${ }^{7}$ El mandato de "igualdad real de oportunidades" implica interpretar la garantía de acceso como algo más que la igualdad formal, ${ }^{8}$ es decir, consiste necesariamente en hablar de inclusión: todos y todas deben recibir educación (estar dentro del sistema), pero bajo ciertas condiciones. En este trabajo, me propongo analizar los distintos alcances que tiene tan sólo uno de los componentes del derecho a la educación: la accesibilidad. Esto permitirá identificar el alcance de las obligaciones concretas que asumen los Estados en lo que respecta al acceso a la educación, a fin de conocer desde dónde deben mirarse, y resolverse, las frecuentes situaciones de desigualdad que se dan en materia de educación y que en muchos casos han sido reclamadas en términos administrativos y/o judiciales.

5 Sostiene Puiggrós que en el mismo acto del descubrimiento de América se encuentra la base de la desigualdad en materia educativa. La autora toma como eje fundamental el acto de lectura del Requerimiento, por el cual se notificaba a los indígenas, en lengua castellana, que el papa - representante de Dios en la Tierra - había entregado una parte del continente americano a los españoles y otra parte a los portugueses. La relación pedagógica entre americanos y españoles se establecía, entonces, como una relación de dominación. Cfr. Puiggrós, Adriana, Qué pasó en la educación argentina: breve historia desde la conquista hasta el presente, Buenos Aires, Galerna, 2003, p. 27.

6 PNUD, Objetivos de Desarrollo Sostenible (ODS). Objetivo 4: educación de calidad, 2015, disponible en: http://www.undp.org/content/undp/es/home/mdgoverview/post-2015-development-age nda.html; UNICEF, The Right of Children with Disabilities to Education, Position Paper, 2012, disponible en: http: / / www.unicef.org/ceecis/IEPositionPaper_ENGLISH.pdf; UNESCO, Situación educativa de América Latina y el Caribe: hacia la educación de calidad para todos al 2015, 2013, disponible en: http: / / www.unesco.org/new/fileadmin/MULTIMEDIA / FIELD/Santiago/images/SI TIED-espanol.pdf (fecha de consulta: 10 de julio de 2017), entre otros. La desigualdad educativa ha sido fuertemente desarrollada desde las ciencias sociales; sin embargo, tiene un desarrollo escaso en el ámbito jurídico.

7 Rawls, John, Teoría de la justicia, México, Fondo de Cultura Económica, 1995; Fiss, Owen, Una comunidad de iguales, Buenos Aires, Miño y Dávila, 2002; Saba, Roberto, Más allá de la igualdad formal ante la ley. ¿Qué les debe el Estado a los grupos desaventajados?, Buenos Aires, Siglo XXI, 2016.

8 Rodino, Ana, "La educación con enfoque de derechos humanos como práctica constructora de inclusión social”, Revista Informe de Investigaciones Educativas, núm. especial sobre educación en derechos humanos, 2011. 
Esta revista forma parte del acervo de la Biblioteca Jurídica Virtual del Instituto de Investigaciones Jurídicas de la UNAM

A este fin, trabajaré con la clasificación de obligaciones que, conforme a la OG-13, han asumido los Estados en materia de acceso a la educación. ${ }^{9}$ En primer lugar, me referiré a la (II) obligación de no discriminación normativa y, posteriormente, a la obligación de no discriminar por situaciones de hecho (fácticas) que impiden el acceso al derecho, vinculadas con (III) la obligación de garantizar la accesibilidad material y (IV) la accesibilidad económica, definiendo el contenido que debe darse a cada una de ellas. Luego y más allá de lo que dispone la OG-13, considero que es posible sumar la (V) obligación de garantizar la accesibilidad simbólica. Por último, (VI) estableceré algunas conclusiones.

\section{OBLIGACIÓN DE NO DISCRIMINACIÓN: ELIMINACIÓN} DE TODO TIPO DE DISCRIMINACIÓN NORMATIVA

El acceso a la educación requiere, en primer lugar, la eliminación de todo tipo de discriminación normativa que impida, limite o restrinja el acceso a la educación. No quiero sostener con esto que no existan normas que regulen el acceso a la educación y que realicen clasificaciones a tal fin. La mayoría de las normas clasifican de alguna manera; sin embargo, la obligación de eliminar todo tipo de discriminación normativa exige indagar por las razones (o sinrazones) de dicha clasificación. ${ }^{10}$

Los Estados latinoamericanos han realizado una apuesta fuerte por la educación, sin dejar de considerar, en general, a los grupos excluidos. Por ejemplo, en Argentina, desde la creación del sistema educativo, la apuesta fue robusta, pues todos los niños y las niñas debían asistir a clase, siendo una obligación directa de los adultos responsables cumplir con este mandato. ${ }^{11}$

9 Más allá de las obligaciones aquí trabajadas referidas al acceso a la educación, la OG establece obligaciones específicas que se derivan de los derechos sociales: adopción de medidas, no regresividad, progresividad, respetar, proteger y cumplir. Estas obligaciones, si bien no serán abordadas en profundidad, serán referenciadas en lo que respecta a las acciones concretas de los Estados en materia de acceso a la educación.

10 Sobre el punto, véase Clérico, Laura y Aldao, Martín, "Nuevas miradas de la igualdad en la jurisprudencia de la Corte Interamericana de Derechos Humanos: la igualdad como redistribución y como reconocimiento”, Estudios Constitucionales, vol. 9, núm. 1, 2011.

11 En Argentina, la Ley núm. 1.420 de Educación común (de 1884). 
Esta revista forma parte del acervo de la Biblioteca Jurídica Virtual del Instituto de Investigaciones Jurídicas de la UNAM

Esta garantía de escolarización se ha mantenido a lo largo de los años, representando la situación de las personas con discapacidad la discriminación más visible. En este sentido, las personas con discapacidad siguen padeciendo de una fuerte situación de desigualdad, ya que si bien no se niega el derecho que tienen de acceder a la educación, éste se lleva a cabo a través de escuelas distintas ("escuelas especiales”), configurándose una clara violación al artículo 24 de la Convención sobre los Derechos de las Personas con Discapacidad. ${ }^{12}$

Más allá de esta situación particular, la discriminación irrazonable (injustificada) pareciera no ser el problema en materia de educación, puesto que es bastante sencilla de identificar. El problema existe cuando se analiza la situación con una lupa más amplia: la de la igualdad real de oportunidades. Esta mirada implica que aun cuando se garantice el acceso a todos / as normativamente, aquellos que viven en ciertos contextos (personas con discapacidad en una sociedad que impone barreras físicas y actitudinales, personas en situación de desplazamiento forzado) o lugares (los niños y las niñas que habitan en zonas pobres de las ciudades), o se encuentran en ciertas posiciones (ser mujer, perteneciente a pueblos originarios), se enfrentarán con fuertes dificultades para acceder (y continuar) al sistema educativo. ${ }^{13}$ Estos grupos están, en general, ante una situación de "discriminación interseccional”. Ello implica asumir que "la discriminación... no solo fue ocasionada por múltiples factores, sino que derivó en una forma específica de discriminación que resultó de la intersección de dichos factores, es decir, si alguno de dichos factores no hubiese existido, la discriminación habría tenido una naturaleza diferente". ${ }^{14}$

Así, lo que se debe garantizar es un "acceso igualitario real a la educación”; pero ¿qué implica esta obligación? Ésta consiste en garantizar la accesibilidad material, la accesibilidad económica y también simbólica.

12 Este artículo dispone que "Los Estados Partes reconocen el derecho de las personas con discapacidad a la educación. Con miras a hacer efectivo este derecho sin discriminación y sobre la base de la igualdad de oportunidades, los Estados Partes asegurarán un sistema de educación inclusivo a todos los niveles así como la enseñanza a lo largo de la vida...”.

13 Salvioli, Fabián, Educación en derechos humanos: políticas públicas para democracias substanciales, La Plata, 2006, disponible en: http://www.dhnet.org.br/educar/1 congresso/1_c2006_fabi an_salvioli.pdf.

14 Corte IDH, Caso Gonzales Lluy y otros vs. Ecuador, Sentencia del 1o. de septiembre de 2015 (Excepciones preliminares, fondo, reparaciones y costas), Serie C 298, párr. 290. 
Esta revista forma parte del acervo de la Biblioteca Jurídica Virtual del Instituto de Investigaciones Jurídicas de la UNAM

\author{
III. ACCESIBILIDAD MATERIAL: ELIMINACIÓN \\ DE TODO TIPO DE BARRERAS QUE DE HECHO IMPIDEN \\ U OBSTACULIZAN EL ACCESO A LA EDUCACIÓN
}

En ciertos casos no alcanza sólo con eliminar de las normas las causales de discriminación irrazonable que impidan el acceso a la educación, sino que para garantizar el goce efectivo de este derecho (en términos de igualdad real), recaen sobre el Estado un conjunto de obligaciones bien concretas, a saber:

\title{
1. Existencia de establecimientos educativos
}

El acceso a la educación requiere, en primer lugar, de la existencia de establecimientos educativos. Éstos deben existir bajo algunas condiciones:

\section{A. Según las necesidades de la población}

Esto implica la obligación de los Estados de crear y sostener establecimientos educativos conforme a las necesidades de cada zona o barrio. No alcanza con tener determinado número de establecimientos, que puede ser muy alto, si éstos se encuentran ubicados sólo en ciertos sectores de la ciudad, o cuando los que existen no son suficientes para responder a las demandas de la zona. Así, entiendo que tampoco alcanza con que existan establecimientos educativos, pero que ellos queden a una distancia que implique a los niños, niñas y adolescentes tener que tomar algún tipo de transporte para poder llegar. Esto es así, ya que el hecho de ir a la escuela no supone solamente estar sentado frente a un docente durante algunas horas, sino que implica mucho más. Trasladar a las personas, en la mayoría de los casos menores de edad, de un lugar a otro, en principio, pareciera no ser una respuesta suficiente del Estado. ${ }^{15}$ Los niños y las niñas deben poder asistir

15 En este caso, el criterio que debería tomarse en cuenta es la "razonabilidad" de la medida. De esta manera, si los/as menores tienen que caminar dos horas para llegar a la escuela, no pareciera ser razonable; por lo tanto, no se estaría garantizando la accesibilidad del derecho. Sin embargo, si la escuela más cercana está a media hora en transporte, y éste es gratuito, en 
Esta revista forma parte del acervo de la Biblioteca Jurídica Virtual del Instituto de Investigaciones Jurídicas de la UNAM http://www.juridicas.unam.mx/ https://biblio.juridicas.unam.mx/bjv https://revistas.juridicas.unam.mx/ DOI: http://dx.doi.org/10.22201/iij.24487872e.2018.18.12100

a escuelas cercanas a su domicilio o, en todo caso, poder elegir (ellos/as o los/as adultos/as responsables) a dónde quieren educarse. La presencia de estas situaciones (falta de vacantes o de escuelas cercanas que hacen necesario el transporte, entre otras) indica que el Estado no está cumpliendo con su obligación de crear y sostener escuelas conforme a las necesidades de la población. Para cumplir con esta obligación, los Estados deberán:

a) Obtener y producir información y estadísticas con el objeto de conocer la situación actual de la matrícula e ir proyectando la creación de nuevas escuelas o readaptando las existentes.

b) Crear y sostener escuelas de acuerdo con las necesidades de la población y de la zona.

c) Prever los gastos de creación, mantenimiento y readaptación de edificios escolares, docentes y personal administrativo en el presupuesto y ejecutarlos. ${ }^{16}$

d) Formar docentes para tales establecimientos con condiciones de trabajo adecuadas.

e) Cantidad de docentes acorde con el número de alumnos/as.

f) Disponer de material didáctico/biblioteca conforme a las necesidades de cada una de las escuelas y/o niños, niñas y adolescentes que asisten.

g) Disponer de espacios de recreación adecuados (salones de música, de deportes, etcétera).

\section{B. De calidad}

Ahora bien, no alcanza sólo con que existan escuelas, sino que además los establecimientos deberán cumplir con condiciones de calidad. En este sentido, no cualquier espacio cerrado puede convertirse en un aula y/o escue-

principio, pareciera que se han tomado medidas para hacer accesible el derecho a la educación. Agradezco al/la evaluador/a la advertencia sobre el punto.

16 El vínculo con el presupuesto resulta fuerte en ciertos casos, como Brown v. Board of Education of Topeka, de la Suprema Corte de Estados Unidos (347 U.S. 483, Sentencia del 17 de mayo de 1954), y la sentencia del TEDH en D. H. y otros c. República Checa (57325/00, Sentencia del 13 de noviembre de 2007, “Ostrava”), donde los niños y las niñas negros/as y de origen romaní podían asistir a la escuela, pero éstas eran escuelas menos subsidiadas, con lo cual se encontraban en peores condiciones que las escuelas a las que asistían los otros niños y niñas. 
Esta revista forma parte del acervo de la Biblioteca Jurídica Virtual del Instituto de Investigaciones Jurídicas de la UNAM

la, sino que debe ser un lugar acorde con las necesidades de las personas menores de edad que allí concurren. ${ }^{17}$ Un buen ejemplo lo constituye el caso de acceso a la educación de las personas con discapacidad motriz. Las personas con discapacidad tienen derecho a educarse en escuelas no especiales; sin embargo, tienen dificultades para ejercer este derecho cuando no pueden acceder a los establecimientos educativos por la falta de accesibilidad en los mismos; por ejemplo, la existencia de barreras físicas (escaleras, desniveles y falta de adaptabilidad en general) y barreras actitudinales (personal capacitado).

\section{En condiciones de seguridad}

Los establecimientos educativos deben encontrarse en condiciones de seguridad para garantizar la integridad física de las personas que allí se localicen. Estas condiciones exigen que los establecimientos deben ser aptos en lo que respecta a infraestructura, accesos, salidas de emergencia, desniveles, rampas, protección contra incendios, instalaciones eléctricas y de gas, ventilación, entre otras. Dichas condiciones incluyen también que los edificios sean aptos para que concurran personas con discapacidad (por ejemplo, forma en que se abren las puertas, baños adaptados, rampas, establecimiento señalizado para no videntes, etcétera).

\section{Establecimientos educativos privados: obligación de controlar}

La creación de establecimientos educativos privados implica hacer efectivo el derecho de los particulares y entidades privadas de establecer y dirigir institutos de enseñanza. Así, no sólo el Estado puede brindar educación, sino que también los particulares pueden ofrecerla. Ahora bien, los particulares pueden “crear escuelas" bajo la supervisión del Estado y cumpliendo ciertos requisitos en lo que respecta a:

17 Esta situación fue debatida en el ámbito de la Ciudad Autónoma de Buenos Aires en el caso conocido como “Aulas Container” (Juzgado CAyT de la CABA núm. 11, Iglesias José Antonio y otros c/ GCBA s/ amparo, Expediente núm. 15.909/0, Sentencia del 10 de julio de 2006). Este asunto se origina por la instalación de espacios modulares como aulas en las escuelas a fin de poder tener más espacio. 
Esta revista forma parte del acervo de la Biblioteca Jurídica Virtual del Instituto de Investigaciones Jurídicas de la UNAM

\section{A. El contenido educativo a impartir en tales establecimientos}

El Estado se reserva el control y puede poner límites (limitando la libertad) a los privados sobre los contenidos que se imparten (y/o se dejan de impartir) dentro de los establecimientos. En estos casos, existe una clara obligación de controlar de parte del Estado respecto de lo que se debe enseñar en dichos establecimientos. ${ }^{18}$

\section{B. El derecho de admisión}

Otro de los puntos cuestionados es el llamado "derecho de admisión" con relación a los/as alumnos/as ejercido por los establecimientos privados (obligación de respetar). Existe de parte de los privados un derecho a contratar libremente (derecho de asociación), y la pregunta es ¡si ese derecho puede ser limitado desde un argumento de igualdad, cuando esa contratación implica prácticas discriminatorias? ${ }^{19}$ En materia de derecho a la educación hay un interés especial del Estado, ya que mediante la educación se busca formar ciudadanos con conciencia democrática. Así, ¿es posible que una escuela sólo reciba niños y niñas de determinada religión o de determinado origen étnico $?^{20}$ Desde una concepción de igualdad robusta, la educación debe fomentar la convivencia democrática; por ello, no sería un criterio válido, si bien es asiduamente usado por las escuelas el criterio de discriminar en razón del origen nacional o cualquier otro tipo de distinción irrazonable. En estos casos, el Estado debe ejercer un fuerte control respecto de dichos establecimientos y las prácticas de admisión. Para que la educación cumpla su función se requiere de un pluralismo en las aulas, así

18 Esta obligación de supervisar ha sido reconocida por la Corte IDH, por ejemplo, en el ámbito del derecho a la salud en el caso Albán Cornejo y otros c. Ecuador (Sentencia del 22 de noviembre de 2007, Serie C 171) y, en forma más reciente, en el caso Gonzales Lluy y otros vs. Ecuador, que ya se había mencionado.

19 Saba, Roberto, op. cit.

20 Por ejemplo, las escuelas religiosas que únicamente aceptan estudiantes de la religión que profesa el establecimiento. En este sentido, si bien la OG-13 aborda la libertad de enseñanza y señala que ésta aplica también para las personas jurídicas o instituciones de enseñanza, otorgando a padres o tutores la libertad de escoger la escuela para sus hijos/as, ésta no puede ser utilizada en forma discriminatoria. Así pues, resulta razonable que una escuela religiosa sólo acepte alumnos/as de esa religión, pero no que los excluya por su condición social. 
Esta revista forma parte del acervo de la Biblioteca Jurídica Virtual del Instituto de Investigaciones Jurídicas de la UNAM

como la existencia de diversas perspectivas, y esto no puede ser restringido por la libertad de los particulares.

\section{Gratuidad}

En la mayoría de los establecimientos educativos privados se dan importantes sumas de dinero a fin de poder educar allí a los/as niños/as. La segmentación educativa, representada por la diferente oferta escolar con un fuerte peso de la educación privada, reproduce y genera grandes desigualdades. Sin embargo, entiendo que la solución se encuentra en la educación pública, esto es, aquella que cae en cabeza directa del Estado. Este último puede evitar estas disparidades extremas subiendo el piso de la educación pública. Si la educación pública diera cuenta de las obligaciones mínimas (diversificar las propuestas educativas, ampliar la jornada, la oferta de educación bilingüe), la educación privada tendería a desaparecer. La obligación del Estado, entonces, es mantener un sistema educativo público que permita iguales posibilidades para todos/as, y que las familias que deseen enviar a sus hijos a la escuela pública opten por ella.

\section{Garantizar el acceso real al establecimiento educativo}

Los Estados están obligados también a garantizar el acceso real al sistema educativo (obligación de cumplir: facilitar y proveer), y para esto, ellos deben realizar una serie de acciones más allá de la creación de establecimientos educativos. Entre ellas:

\section{A. Condiciones de acceso previas al establecimiento}

Debe garantizarse que todos/as los/as menores puedan llegar al establecimiento. Por tanto, no sólo deben existir establecimientos cercanos a los domicilios o transporte escolar (excepcionalmente), sino además garantizarse otras condiciones; por ejemplo, veredas o calles adecuadas en donde los/as niños/as puedan caminar, o condiciones de seguridad ante situaciones de violencia (robos, calles o rutas sin acceso peatonal). 
Esta revista forma parte del acervo de la Biblioteca Jurídica Virtual del Instituto de Investigaciones Jurídicas de la UNAM

\section{B. Eliminar las barreras administrativas y /o facilitar trámites}

Esta obligación implica eliminar todas las barreras administrativas que impidan a un/a niño/a o adolescente ingresar a un establecimiento educativo. En este sentido, por ejemplo, la falta de un documento que acredite la identidad no puede constituirse en una barrera para el ejercicio del derecho a la educación.

Este planteo fue abordado por la Corte IDH en el caso de las Niñas Yean y Bosico. ${ }^{21}$ En este asunto, el Estado dominicano negó la nacionalidad a las niñas Yean y Bosico, solicitada mediante el procedimiento de declaración tardía, a pesar de haber nacido en territorio dominicano. La falta de reconocimiento de la nacionalidad no sólo ponía a las niñas en una situación de peligro inminente de ser expulsadas del país, sino que además no podían ingresar a la escuela ni acceder a servicios de salud y asistencia social por carecer de un documento de identidad. La Corte reconoce que "el Estado debe cumplir su obligación de garantizar el acceso a la educación primaria y gratuita de todos los niños, independientemente de su ascendencia u origen, que se deriva de la especial protección que se debe brindar a los niños". ${ }^{22}$

Si bien las escuelas, en ciertos casos, aceptan alumnos/as indocumentados/as, el problema se presenta cuando terminan la educación primaria y/o secundaria, pues no pueden obtener el título que acredita la culminación de tales estudios, o, peor aún, cuando todavía sin terminarla, dejan de asistir al establecimiento educativo. En este sentido, por ejemplo, en Argentina, las personas indocumentadas, en general, en estos últimos años no tienen dificultades para acceder al sistema educativo; pero la falta de documento identificatorio constituye un impedimento para el goce de otros derechos (salud, trabajo, asistencia social y vivienda), que complementan y se hacen posibles mediante el derecho a la educación.

Corresponde al Estado, entonces, eliminar todo tipo de barreras, creando procedimientos rápidos y no burocráticos para la obtención de la documentación necesaria, realizando un seguimiento de aquellos casos que no los presentan, y estimulando e informando sobre la necesidad de contar con un documento que acredite la identidad.

21 Corte IDH, Caso de las Niñas Yean y Bosico vs. República Dominicana, Sentencia del 8 de septiembre de 2005 (Excepciones preliminares, fondo, reparaciones y costas), Serie C 130.

22 Ibidem, párr. 244. 
Esta revista forma parte del acervo de la Biblioteca Jurídica Virtual del Instituto de Investigaciones Jurídicas de la UNAM

\section{Eliminar los prejuicios respecto de ciertos grupos}

Con relación a este punto, se manifestó la Corte IDH en el caso Gonzales Lluy y otros vs. Ecuador. ${ }^{23}$ Aquí lo que se debatía era la responsabilidad del Estado por la discriminación que había padecido la niña Talía Gonzales Lluy, que por ser portadora de VIH fue expulsada de la escuela (y rechazada por otras) "por el presunto peligro que generaba para sus compañeros"; sin embargo, este riesgo no fue demostrado. Por el contrario, la Corte reconoce que

las personas con VIH han sido históricamente discriminadas debido a las diferentes creencias sociales y culturales que han creado un estigma alrededor de la enfermedad. De este modo, que una persona viva con VIH/SIDA, o incluso la sola suposición de que lo tiene, puede crear barreras sociales y actitudinales para que esta acceda en igualdad de condiciones a todos sus derechos. ${ }^{24}$

Si bien en el caso se reconoce que el Estado había avanzado respecto de la eliminación de los prejuicios contra este grupo de personas, queda claro que esa situación en ningún caso puede ser trasladada a las personas y que los Estados tienen obligaciones concretas de eliminar los prejuicios en contra de los grupos sojuzgados (obligación de proteger). Así pues, la Corte sostuvo que

las autoridades educativas no tomaron medidas para combatir los prejuicios en torno a la enfermedad de Talía. En lo relativo al derecho a disponer de información oportuna y libre de prejuicios, la antigua Comisión de Derechos Humanos de las Naciones Unidas indicó la necesidad que los Estados tomen las medidas necesarias de educación, capacitación y programas mediáticos a fin de evitar la discriminación, el prejuicio y el estigma en todos los ámbitos contra las personas que padecen $\mathrm{VIH} /$ SIDA..$^{25}$

23 Corte IDH, Caso Gonzales Lluy y otros vs. Ecuador, Sentencia del 1o. de septiembre de 2015 (Excepciones preliminares, fondo, reparaciones y costas), Serie C 298.

24 Ibidem, párr. 236.

25 Ibidem, párr. 263. 
Esta revista forma parte del acervo de la Biblioteca Jurídica Virtual del Instituto de Investigaciones Jurídicas de la UNAM

\section{ACCESIBILIDAD ECONÓMICA: GARANTIZAR LA GRATUIDAD \\ EN EL ACCESO A LA EDUCACIÓN (ALCANCE)}

La accesibilidad económica implica que la educación debe estar al alcance de todas las personas, no pudiendo éstas, por razones económicas, quedar excluidas de este derecho. Así, discutir el alcance del principio de gratuidad establecido en el párrafo 2 del artículo 13 del PIDESC resulta esencial a fin de determinar las obligaciones del Estado en la materia.

El principio de gratuidad exige no realizar cobro alguno por parte del Estado para poder acceder a la educación. Siguiendo a Uprimny, ${ }^{26}$ es posible establecer tres concepciones de gratuidad:

a) La concepción minimalista, que afirma que la gratuidad de la educación implica que sólo los costos de la matrícula y de los derechos académicos deben ser eximidos de pago.

b) La concepción intermedia, que señala que, además de los anteriores costos, la gratuidad de la educación implica que deberían subsidiarse los costos indirectos, como uniformes, libros y transporte.

c) Una tercera concepción, más robusta, plantea que la gratuidad debe cubrir gastos compensatorios, es decir, que el Estado tendría que subsidiar el costo de oportunidad en que incurre la familia al enviar a un niño a la escuela.

Considero que la opción "intermedia” es la que más se ajusta a la visión de igualdad robusta, pues significa que el Estado no únicamente debe abstenerse de efectuar algunos cobros, sino que además debe disponer de todas las medidas indispensables para garantizar el acceso a la educación; por ejemplo, mediante la entrega de materiales de estudio. En este sentido, la gratuidad implicará no sólo que los/as niños/as que asistan a la escuela no abonen dinero alguno en concepto de cuota o seguro escolar, sino que también el Estado debe disponer de todas aquellas medidas para que la educación sea posible. Así pues, "los derechos de matrícula impuestos por el gobierno, las autoridades locales o la escuela, así como otros costos directos,

26 Uprimny, Rodrigo, "La gratuidad en educación básica", Bogotá, 2006, disponible en: https: / / docs.escr-net.org/usr_doc/La_Gratuidad_en_Educacion_Basica.pdf. 
Esta revista forma parte del acervo de la Biblioteca Jurídica Virtual del Instituto de Investigaciones Jurídicas de la UNAM

son desincentivos del disfrute del derecho que pueden poner en peligro su realización”. ${ }^{27}$

Este principio de gratuidad se refuerza aún más cuando se establece que la educación es obligatoria; de lo contrario, ¿cómo es posible cobrar por algo que estamos obligados a garantizar?, y ¿qué sucede con aquellas familias que no disponen de los recursos económicos para financiar el acceso a la educación? Asimismo, no alcanza con que la escuela sea gratuita porque no cobra dinero alguno para asistir a ella si los/as alumnos/as no pueden llegar porque viven a más de una hora de viaje y no tienen forma de abonar al transporte escolar. Pensemos también en lo costoso de los materiales de estudios y su falta de disponibilidad en las escuelas, lo que ocasiona que los/as alumnos/as no puedan acceder a ellos. Esto cae dentro de las obligaciones de los Estados. La gratuidad implica, entonces, no sólo el deber de garantizar el no pago de dinero alguno, sino además la obligación de promover que los/as alumnos/as puedan acceder al derecho a la educación en condiciones reales. Para esto es necesario disponer de ayudas económicas para los grupos más vulnerables.

La OG-13 delimita que la gratuidad se refiere a la enseñanza primaria, lo que no excluye que los Estados avancen gradualmente en garantizarla también a nivel secundaria y superior. En ciertos países de la región, esto (gratuidad en los niveles secundaria y superior) ya ha ocurrido. Se aplica así el principio de no regresividad y progresividad..$^{28}$

\section{ACCESIBILIDAD SIMBÓLICA: ADECUACIÓN PARA PERSONAS CON DISCAPACIDAD}

Las acciones estatales, en muchas ocasiones, se tornan insuficientes o inadecuadas para romper con la situación de desigualdad estructural que afecta a ciertos grupos, pues padecen de una falta de reconocimiento. Así, la situación de desventaja de un grupo puede provenir también por cuestiones de falta o insuficiente reconocimiento. Estos grupos se ven afectados por una

27 Observación General núm. 11, Comité DESC, párr. 7.

28 Abramovich, Víctor y Courtis, Christian, Los derechos sociales como derechos exigibles, Madrid, Trotta, 2004. 
Esta revista forma parte del acervo de la Biblioteca Jurídica Virtual del Instituto de Investigaciones Jurídicas de la UNAM

gran injusticia social que se fundamenta en la falta de reconocimiento y valorización de las identidades diversas; esto es, de una falta o de un erróneo reconocimiento de derechos por la existencia de un patrón cultural dominante que excluye e invisibiliza a todo lo que no responde a ese patrón. Esto es llamado por Fraser como injusticia simbólica. ${ }^{29}$

La situación de las personas con discapacidad es un ejemplo claro de cómo las obligaciones de los Estados no pueden limitarse a las de accesibilidad material, ya que a este grupo de personas históricamente no se les ha negado, en general, el derecho a la educación, sino que han sido destinadas a escuelas "especiales" (separadas), en donde concurren la mayoría de los niños/as con discapacidad. Sin embargo, es necesario pensarlo en términos simbólicos: ¿qué implica ir a una escuela distinta? La "separación en espacios segregados reproduce los estereotipos y crea un estigma de inferioridad, que convierte a muchas personas en parias durante su vida adulta". ${ }^{30}$ Por el contrario,

...la educación inclusiva es importante desde el punto de vista social porque ofrece una plataforma sólida para combatir la estigmatización y la discriminación. Un entorno de enseñanza mixto que incluya a las personas con discapacidad permite que se valoren sus contribuciones y que se afronten y eliminen progresivamente los prejuicios y las ideas erróneas. ${ }^{31}$

Lo que se logra al compartir la educación con personas diferentes es que los individuos aprendan a convivir con la diversidad, a respetar al otro/a. Así, el Estado no puede probar que existe un interés estatal por el cual las personas con discapacidad deban concurrir a escuelas diferenciadas.

29 Fraser, Nancy, "La justicia social en la era de la política de la identidad: redistribución, reconocimiento y participación”, en Fraser, Nancy y Honneth, Axel, ¿Redistribución o reconocimiento?, Madrid, Ediciones Morata, 2006.

30 ACIJ, "Una deuda de derechos humanos: la falta de acceso a la escuela de niños/as con discapacidad y de niños con discapacidad que viven en villas. El caso de la CABA”, Buenos Aires, 2014, disponible en: http: / / acij.org.ar/blog/2014/06/19/informe-sobre-la-falta-de-accesoa-la-escuela-de-ninosas-con-discapacidad/. Por su parte, elTEDH tuvo oportunidad de referirse al tema en el caso Ostrava ya mencionado; sin embargo, no se cuestiona por la existencia de escuelas especiales, sino sólo se refiere a las razones por las cuales algunos niños/as iban a esas escuelas.

31 Oficina del Alto Comisionado de la ONU, "Estudio temático sobre el derecho de las personas con discapacidad a la educación”, 25o. periodo de sesiones, 2013. 
Esta revista forma parte del acervo de la Biblioteca Jurídica Virtual del Instituto de Investigaciones Jurídicas de la UNAM

Las formas diversas de discriminación que padecen las personas con discapacidad "van desde la discriminación directa, como por ejemplo la negativa a conceder oportunidades educativas, a formas más «sutiles» de discriminación, como por ejemplo la segregación y el aislamiento conseguidos mediante la imposición de impedimentos físicos y sociales". ${ }^{32}$ En aras de lograr la igualdad, se hace necesario que el Estado realice acciones positivas en favor de las personas con discapacidad, siendo el mandato, al respecto, muy claro: "las personas con discapacidad deben asistir a las mismas escuelas que el resto de las personas y las escuelas, docentes, estudiantes y demás miembros de la comunidad educativa deben adaptarse". ${ }^{33}$ Para esto, el rol de los Estados es fundamental.

Es así que desde hace unos años la discusión gira en torno a la necesidad de que las personas con discapacidad concurran a los mismos establecimientos educativos que el resto de los/as niños/as; sin embargo, el debate no está saldado. Pese a que en muchos casos los niños y las niñas con discapacidad han logrado conseguir una vacante en una escuela "no especial", existen con relación a ellos/as una multiplicidad de barreras actitudinales y físicas. Esto claramente tiene un impacto negativo en su desarrollo educativo y en su valoración como personas. En este sentido, veamos algunas de estas barreras:

- Falta o insuficiente adaptabilidad de los establecimientos educativos en lo que respecta a la accesibilidad física: no existen rampas; los baños no se encuentran adaptados; ciertos espacios son inaccesibles (por ejemplo, las salas de música o de computación) por la presencia de escaleras; hay puertas que no permiten el ingreso; los ascensores no adaptados, etcétera. En consecuencia, a la mayoría de los establecimientos escolares no puede ingresar una persona con discapacidad, o si puede hacerlo, no puede realizarlo en forma autónoma.

- Entrega de títulos diferenciados para las personas con discapacidad.

- Falta de maestros/as de apoyo (que no necesariamente son docentes) en las escuelas comunes, o garantizados, por ejemplo, por el sistema de salud (obra social, seguro de salud).

32 Observación General núm. 5, Comité DESC.

33 Artículo 24 de la Convención sobre los Derechos de las Personas con Discapacidad. 
Esta revista forma parte del acervo de la Biblioteca Jurídica Virtual del Instituto de Investigaciones Jurídicas de la UNAM

Éstas son algunas de las situaciones que deben enfrentar los niños y las niñas con discapacidad, así como los adultos a su cargo, a la hora de "ingresar" a una escuela común. ${ }^{34}$

De esta manera, es necesario que la escuela se adapte a los/as estudiantes; no alcanza con que sólo puedan ir a la escuela, sino que se requiere algo más. La eliminación de barreras (físicas y actitudinales) es una obligación inmediata para los Estados y en ningún caso puede ser trasladada a las familias, pues éste es el compromiso que han asumido en el marco del derecho internacional de los derechos humanos.

\section{CONCLUSIÓN}

Busqué en este trabajo definir ciertas obligaciones concretas que se desprenden del derecho a la educación, en especial en lo que respecta a la accesibilidad, desde una mirada igualitaria robusta. Entiendo que éstas son obligaciones definitivas del Estado, esto es, deben ser cumplidas bajo el "modelo de reglas". ${ }^{35}$ La existencia de una regla implica un mandato de subsunción: dada determinada situación de hecho, el Estado debe cumplir con la obligación, pues en caso de no hacerlo, existe una vulneración del derecho. Las reglas presentan un carácter definitivo, es decir, son cumplidas o no: si se da el supuesto de hecho de la norma, se sigue la solución. No corresponde una ponderación de derechos. Adicionalmente, desde el derecho internacional de los derechos humanos, los tratados conllevan obligaciones generales y específicas para los Estados que los suscriben. En otras palabras, adhiriéndose a un instrumento internacional, el Estado se compromete a la realización de los derechos ahí reconocidos, de tal suerte que las obligaciones que se desprenden no están sujetas a discusión y, por lo tanto, deben cumplirse; de lo contrario, el Estado es sujeto de responsabilidad internacional.

34 Estas situaciones se ven agravadas por otras causas de desigualdad (desigualdad interseccional): ser pobre, ser mujer o no hablar el idioma oficial. Cfr. Samaniego de García, Pilar, Personas con discapacidad y acceso a servicios educativos en Latinoamérica: breve análisis de situación, Quito, Cinca, 2008.

35 Alexy, Robert, Teoría de los derechos fundamentales, trad. de Ernesto Garzón Valdés, Madrid, Centro de Estudios Constitucionales, 1993; Ronconi, Liliana, "Derecho a la salud: un modelo para la determinación de los contenidos mínimos y periféricos", Revista Salud Colectiva, vol. 8, núm. 2, mayo-agosto de 2012. 
Esta revista forma parte del acervo de la Biblioteca Jurídica Virtual del Instituto de Investigaciones Jurídicas de la UNAM

Considero que las obligaciones que aquí se analizaron respecto de la accesibilidad son de cumplimiento inmediato por parte de los Estados que han reconocido el derecho a la educación; además, deberá ser quien deba demostrar que ha avanzado en el cumplimiento del derecho, así como la suficiencia de las medidas adoptadas. ${ }^{36}$ Sin estas garantías básicas, la desigualdad en materia educativa seguirá siendo una constante en la región, lo que implicará un grave estancamiento en la plena vigencia de ése y del resto de los derechos humanos básicos de la población.

\section{BIBLIOGRAFÍA}

ABRAmOVICH, Víctor y COURTIS, Christian, Los derechos sociales como derechos exigibles, Madrid, Trotta, 2004.

AlEXY, Robert, Teoría de los derechos fundamentales, trad. de Ernesto Garzón Valdés, Madrid, Centro de Estudios Constitucionales, 1993.

ClÉRICO, Laura y ALDAO, Martín, "Nuevas miradas de la igualdad en la jurisprudencia de la Corte Interamericana de Derechos Humanos: la igualdad como redistribución y como reconocimiento", Estudios Constitucionales, vol. 9, núm. 1, 2011.

FISs, Owen, Una comunidad de iguales, Buenos Aires, Miño y Dávila, 2002.

FRASER, Nancy, "La justicia social en la era de la política de la identidad: redistribución, reconocimiento y participación”, en FRASER, Nancy y HonneTH, Axel, ¿Redistribución o reconocimiento?, Madrid, Ediciones Morata, 2006.

PUiggrós, Adriana, Qué pasó en la educación argentina: breve historia desde la conquista hasta el presente, Buenos Aires, Galerna, 2003.

Rawls, John, Teoría de la justicia, México, Fondo de Cultura Económica, 1995.

Rodino, A., "La educación con enfoque de derechos humanos como práctica constructora de inclusión social", Revista Informe de Investigaciones Educativas, núm. especial sobre educación en derechos humanos, 2011.

36 En este sentido, la creación de establecimientos resulta de difícil cumplimiento inmediato, pues requiere contratar personal, construir y/o adaptar edificios, entre otros aspectos. Sin embargo, el Estado deberá adoptar medidas provisorias intermedias para garantizar el derecho a la educación de los niños y las niñas. 
Esta revista forma parte del acervo de la Biblioteca Jurídica Virtual del Instituto de Investigaciones Jurídicas de la UNAM

RONCONI, Liliana, "Derecho a la salud: un modelo para la determinación de los contenidos mínimos y periféricos”, Revista Salud Colectiva, vol. 8, núm. 2, mayo-agosto de 2012.

SABA, Roberto, Más allá de la igualdad formal ante la ley. ¿Qué les debe el Estado a los grupos desaventajados?, Buenos Aires, Siglo XXI, 2016.

SALVIOLI, Fabián, Educación en derechos humanos: políticas públicas para democracias substanciales, La Plata, 2006, disponible en: http://www.dhnet.org. br/educar/1 congresso/1_c2006_fabian_salvioli.pdf.

Samaniego de García, Pilar, Personas con discapacidad y acceso a servicios educativos en Latinoamérica: breve análisis de situación, Quito, Cinca, 2008.

TOMASEVSKI, Katarina, El asalto a la educación, Barcelona, Itermon Oxfam, 2004.

UPRIMNY, Rodrigo, "La gratuidad en educación básica”, Bogotá, 2006, disponible en: https://docs.escr-net.org/usr_doc/La_Gratuidad_en_Educacion_ Basica.pdf.

\section{Sentencias e informes}

ACIJ, "Una deuda de derechos humanos: la falta de acceso a la escuela de niños/as con discapacidad y de niños con discapacidad que viven en villas. El caso de la CABA”, Buenos Aires, 2014, disponible en: http: / / acij. org.ar/blog/2014/06/19/informe-sobre-la-falta-de-acceso-a-la-escuela-deninosas-con-discapacidad/.

CORTE IDH, Caso Albán Cornejo y otros c. Ecuador, Sentencia del 22 de noviembre de 2007, Serie C 171.

Corte IDH, Caso de las NiñasYean y Bosico vs. República Dominicana, Sentencia del 8 de septiembre de 2005 (Excepciones preliminares, fondo, reparaciones y costas), Serie C 130.

CorTe IDH, Caso Gonzales Lluy y otros vs. Ecuador, Sentencia del 1o. de septiembre de 2015 (Excepciones preliminares, fondo, reparaciones y costas), Serie C 298.

JuzGado CAyT DE LA CABA núm. 11, Iglesias José Antonio y otros c/ GCBA s/ amparo, Expediente núm. 15.909/0, Sentencia del 10 de julio de 2006 (Aulas Containers). 
Esta revista forma parte del acervo de la Biblioteca Jurídica Virtual del Instituto de Investigaciones Jurídicas de la UNAM

Oficina Del Alto Comisionado DE LA ONU, "Estudio temático sobre el derecho de las personas con discapacidad a la educación”, 25o. periodo de sesiones, 2013.

PNUD, Objetivos de Desarrollo Sostenible (ODS). Objetivo 4:educación de calidad, 2015, disponible en: http://www.undp.org/content/undp/es/home/mdgo verview/post-2015-development-agenda.html.

Suprema Corte de los Estados Unidos, Brown v. Board of Education of Topeka, 347 U.S. 483, Sentencia del 17 de mayo de 1954.

TEDH, D. H. y otros c. República Checa (57325/00, Sentencia del 13 de noviembre de 2007, "Ostrava”).

UNESCO, Situación educativa de América Latina y el Caribe: hacia la educación de calidad para todos al 2015, 2013, disponible en: http: / /www.unesco.org/ new /fileadmin/MULTIMEDIA / FIELD / Santiago/images/SITIED-espanol.pdf.

UNICEF, The Right of Children with Disabilities to Education, Position Paper, 2012, disponible en: http://www.unicef.org/ceecis/IEPositionPaper_ENGLI SH.pdf. 